\title{
Notes on the Physical Conditions existing within the Line from Start Point to Portland.
}

By

H. M. Kyle, D.Sc.

DURING the trawling work of the past year within and around the bays on the south coast of Devon, my attention was drawn to the peculiar phenomena displayed by the tides and currents in Start Bay, and a subsequent endeavour to trace their connections and consequences led to a wider survey of the region within the line from Start to Portland. The bottom samples brought up by the trawl and lead afforded excellent opportunities of ascertaining the nature and distribution of the different soils, and thus of tracing out their changes during the seasons. My own observations, moreover, were supplemented by those of the friendly Brixham fishermen, who had many years' experiences behind them. Their theories, it is true, were somewhat numerous and divergent, as becomes such an energetic and independent race, but the phenomena were described with a wonderful definiteness and unanimity. Knowledge of the bottom-soil-its changes through the month and year-and of the tidal phenomena is absolutely essential to the fisherman because his living depends upon it, so that one need not be surprised at, though appreciating, the great accuracy with which they can tell where they are and what they should catch in their trawls from a brief examination of the soil brought up by the lead.

In addition to the records of the trawl and lead, dredgings were taken in the usual manner by means of a canvas bag laced inside the ordinary dredge, but these were comparatively few in number. The region under investigation is an awkward one as regards weather even in the best of years, and the weather of the past year was exceptional in its severity. The result was that the limited time at our disposal was shortened on every occasion throughout the year, and the offshore grounds were only partially investigated. I am obliged, therefore, to rely on the Admiralty charts for the areas not investigated, but of the 
relations between tides and bottom-soil they, of course, give no account, and it is with these the present paper will deal.

In the various pilot guides to the English Channel a great amount of information is given with regard to the tides in the different regions, and much light is thrown on the circulation of the water within the line from Start Point to Portland and its relation to the tides at the mouth of the Channel; but here, again, the inshore currents are barely mentioned, and the relation of the currents generally to the formation and changes of the bottom-soil not at all.

Several papers contributed by Mr. H. N. Dickson to this Journal (vol. ii.) deal with the distribution of surface temperatures in the English Channel. Comparatively few records were taken within the area here considered, but during the summer of 1891 it was found that in Start Bay,* so called, a warm upper stratum of water was superposed upon a cold lower layer nearer the bottom. In other respects than temperature the two strata were alike. Special emphasis was laid by Dickson upon this discovery, even though observations made in the succeeding winter failed to corroborate it. It showed that the colder waters from west of the Start were able to penetrate under the almost stagnant upper layers within the Great West Bay.

With regard to the action of waves and currents on the shore a great deal of literature exists, but it is unnecessary to enter into this aspect in any detail. Reference need only be made to the paper of Vaughan Cornish on the famous Chesil Beach near Portland, and to the recent work of Wheeler on the Sea Coast: Its Destruction and Protection. In the former the much-disputed origin of the Chesil Beach is discussed, and a theory stated which seems to accord well with the phenomena observed. As will be shown later, this theory is accepted here and applied to phenomena very similar, though on a smaller scale, at the other extreme of the area, namely, Slapton Sands in Start Bay. In the latter work an interesting account is given of the actual condition of the shores and the littoral drift on the south coast. Reference will be made to it later.

The Great West Bay is 48 miles across from Start Point to Portland, and extends 20 miles inwards. Its area is about 650 square miles. It opens to the south-west, so that its easterly arm towards Portland

* Considerable doubt exists as to the right name to apply to the region within the line from Start Point to Portland. Dickson refers to it as Start Bay, but this is obviously incorrect. Wheeler calls it Lyme Bay, but Lyme Bay is more usually restricted to the northern portion from Hope's Nose or Straight Point to Portland. It seems advisable to have a distinct name, however, because Start Point and Portland form the natural boundaries to a compact series of phenomena, and the name Great West Bay, used by Mr. A. R. Hunt (The Evidence of the Skerries Shoal on the Wearing of Fine Sand by Waves, 1897), has been adopted in this paper. 
is fully exposed to the southerly and westerly gales, but sheltered from the easterly. Conversely, the arm which extends out to the Start is sheltered from the westerly gales, and only the easterly and southeasterly winds affect it strongly.

It has long been known as a good fishing-ground, and at the present day from seventy to eighty of the Brixham boats trawl over it regularly throughout the year. From the point of view of the fisheries this area is of great interest, for it displays within comparatively narrow limits all the important biological problems in connection with the life histories of food-fishes, as well as the physical conditions with which those life histories are so closely related.

\section{Tides and Currents.}

The movements of the tides in the English Channel are complicated by the numerous bays and inlets of the French and English coasts. In the centre of the Channel the periodic ebb and flow is fairly regular, but even there the cross eurrents caused by in-draughts into the various bays on both coasts produce a rotary motion at the changes of the tides, which is only approximately constant as regards direction and duration. Without entering too far into the details which may be found in Channel pilot books, the tidal currents and their strengths may be referred to so far as they concern the Great West Bay.

The Channel is divided into three main regions: the first lies to the west of the Lizard in Cornwall; the second from the Lizard to Start Point; and the third from Start Point to Beachy Head. In the first division the state of the tides is always the reverse of that in the third, i.e. with regard to ebb and flood ; in the second region it is "intermediate," agreeing for one half of the tidal period with the outside main tidal stream, and for the other half with the "true Channel stream " between Start Point and Beachy Head. There is no definite line of demarcation, however; what happens is that whilst the "true Channel stream" is flowing, the condition intermediate between ebb and flood, i.e. slack water, is gradually passing from the Lizard to the Start until it reaches the latter point two hours before high water at Dover. To the west of Start Point, therefore, the ebb is going to the west for one hour whilst the flood to the east of Start Point is still travelling to the east. The "true Channel stream," as is well known, suddenly changes after high water at Dover throughout the third region and ebbs to the west. For the short space of one hour the direction of the tidal current is the same throughout the entire Channel, i.e. to the west, then the flood begins to make at the western end, and for the next four hours the second region is the centre of opposing forces. In the western end of 
the Channel the flood is deflected to the north for one hour, and then flows steadily to the east; in the centre of the second region the antagonistic forces produce a definite spell of slack water when they meet, but in the eastern end near Start Point the oncoming flood is deflected to the south and south-east for two hours before it is able to overcome the opposing ebb current. During the same period the ebb to the east of the Start is deflected first of all to the south of west, then to the north, and there is no period of slack water. During the last part of the ebb, therefore, the tidal current is setting directly into the Great West Bay.

It thus appears that the Great West Bay participates in the effects of the conflict between the "true Channel stream," and the "intermediate stream," and these effects are such that a definite spell of slack water occurs on the last of the flood, ${ }^{*}$ and that there is an inset on the last of the ebb. $\dagger$ It is evident, therefore, that these conflicting currents tend on the whole to weaken the tides in the Great West Bay, and the peculiar disposition of the bottom-soil there is in part due to this cause.

The strength of the tidal currents is manifested by the rate. Whilst the rate outside is over two knots per hour at springs, within the Great West Bay, off Berry Head, it is less than one knot. The centre of this region, in fact, is almost at rest so far as the tides are concerned, and farther in towards the land, off Beer Head, the currents move definitely round a complete circle during the tidal period.

At the two extreme corners the currents rush in and out with great velocity. The latter phenomenon is associated with, and partly the result of, the heaping up of the waters within a confined area. When the flood-tide passes round the Start it has to contend against not merely the rising ground, but also a sheet of water which will stand compression only to a limited extent. The main stream is consequently deflected away from the bay towards Portland. For the first three hours of flood the water-level steadily rises all over the area, and the trend of the current all along the shore is towards the east. When high water is reached the current is still eastward outside and in the easterly portion of Lyme Bay, but as we pass in towards the land of the westerly portion, the current gradually gets slower, until it ceases altogether, and finally changes its direction and flows to the west. The waters heaped up at the head of the bay by the rising tide must find some outlet after high water, and whilst the eastward current outside has still some three hours to run. As we pass,

* Except, perhaps, to the east of the bay, near Portland.

+ The direction of the surface currents here, as elsewhere in the English Channel, is greatly determined by the prevailing winds. Cf. W. Garstang, Journ. M. B. A., v. p. 199.

NEW SERIES.-VOL. VI. NO. 4. 
on the one hand, from Beer towards Portland, the stream gradually increases from almost nothing in strength to over five knots per hour. As we pass backward along shore from Beer towards the Start we pass through Teignmouth Bay, where the current is scarcely felt, Torbay, where it is uncertain and variable in direction, until we come to Berry Head and Mudstone Ledge, where the current is setting to the westward.

On the shore of the western half of the area there is, therefore, a backward eddy during the latter half of the flood-tide. Wheeler, in describing this peculiar phenomenon for Start Bay, imagined that the flood-tide was deflected from the cliffs forming the north-eastern boundary of Start Bay, and thus entered the bay from its north-eastern aspect. Apart from the inherent improbability of such a thing, this explanation leaves out of count the presence of the backward eddy over Mudstone Ledge close to Berry Head.

Along Slapton Sands, in Start Bay, the current sets towards Start Point the last half of the flood and the whole of the ebb, i.e. for nine hours out of the twelve. Along Chesil Beach, at the other corner, the current sets towards Portland also for nine hours out of twelve, but there it is during the last part of the ebb and the whole of the flood.

The tidal phenomena close to Portland repeat what has already been described as occurring off Beer Head. Two miles west of Portland Bill the direction of the currents turns round a complete circle, so that after three hours of ebb-tide the current sets northerly into the bay, and to counterbalance this inset there is an outward eddy along Chesil Beach. This northerly set of the current is probably due to the fact that the flood is already making to the west of Start Point. To the west of Portland Bill, therefore, there is a circular motion of the waters during the last part of the ebb.

The comparison of the currents at the two extreme ends of the area may be carried still farther. At the eastern end the stream passing round Portland Bill meets with an opposing ebb and eddy from beyond, and thus helps to form the "race," which passes on to and over the great sandbank known as the Shambles. At the western extremity the eddy issuing from Start Bay also forms a race with the opposing flood-tide coming from the west, and this race extends obliquely from the shore for nearly a mile in a south-westerly direction. The outgoing eddy, however, is weak in comparison with that at Portland, so that the race is not a strong one, and the sandbank, instead of being in the direct line of the race, lies farther to the north-east on the line of the flood-tide.

The conditions, so far described, obtain generally throughout the year, but are more particularly marked during spring-tides. During neaps, the water is almost stagnant over the whole western area, and the currents along shore are feeble and uncertain in direction. In Teignmouth 
Bay there is practically no current one mile from the shore. The tide sets directly on to the beach in its northerly portion, and the only currents along shore are caused by projecting headlands, e.g. Clerk Point, sending off the incoming tide on each side in different directions. At the southern end of the bay the incoming tide sets along the projecting headland of Hope's Nose, and there is thus a slight current along shore.* In Torbay the central portions are even more stagnant than in Teignmouth Bay, but on the beach we have the same phenomenon of currents acting in opposite directions. Paignton Head, in the centre of the bay, divides up the incoming tide, and there is a current on each side of it-the one tending across Brixham breakwater to Berry Head, the other towards Torquay and Hope's Nose.

Sometimes, as the result of storms either within the area or beyond in the Channel, these currents may be reversed, but in general they are well marked.

Within Start Bay during neaps there is very little current in the centre of the bay, and the eddy along shore is not so strong as during spring-tides. During the latter periods the eddy rushes out round the Start at a rate exceeding two knots per hour. This eddy extends about a mile from the shore off Torcross, and during the ebb the current sets straight across the Skerries in a south-south-easterly direction.

\section{DEPTHS AND BotTOM-SOIL.}

The region under consideration lies mostly within the thirty-fathom line. At Start Point the water deepens rapidly, so that within two miles of the shore thirty fathoms is reached. From there the thirty-fathom line runs in an easterly direction until the centre of the bay is reached, when it inclines to the south of east and passes Portland about eight miles off. Within this line the water gradually shoals, and twenty fathoms is reached on a line from Berry Head to Portland. The twentyfathom line is also concave, with the concavity more marked towards Portland. The ten-fathom line follows roughly across the outlying headlands of the numerous bays and indentations round the coast, being nowhere more than three miles from the shore, and in some places approaching it to within a few yards.

The general rise in the bottom-level is fairly uniform and regular, except along the western side, where important modifications occur. Within half a mile of Start Point, to the north-east, the water shoals rapidly from nine fathoms to four, and a little farther to only two.

* According to Mr. Taverner, the Fisheries Inspector of the Devon Sea Fisheries Committee, the general trend of the current here is from Babbacombe towards Hope's Nose ; that is to say, that the eddy which makes itself so evident in Start Bay is already felt in Teignmouth Bay. 
From thence the sandbanks of the Skerries extend in a north-easterly direction for three miles. The tops of the banks lie from two to five fathoms below the surface, but between them the water deepens to nine or more fathoms. On the outer side the slope of the banks is very steep, and more so toward the end away from the Start. In some places it descends from five fathoms to eighteen within a hundred yards. On the inner side the slope is more gradual, but when from four to five fathoms are reached there is a sudden dip down to about seven. This is caused by the central channel of the bay, which narrows as it approaches the Start, and is generally about nine fathoms deep. Half a mile off Hallsands, in June, 1902, a depth of fifteen fathoms was obtained by the lead, and according to the Brixham fishermen this part is "full of pits."

At the other extremity of the Skerries Bank there is a sudden dip to fourteen fathoms at the Bell Buoy, and from there across to the Mewstone, on the far side of Dartmouth fairway, the depth approaches twenty fathoms. Beyond the east Blackstone, half a mile to the east of the Mewstone, there is a bank of sand well known to the Brixham men, but not clearly indicated on the charts. It begins on the southerly aspect of the Blackstone, and runs in a north-easterly direction for nearly a mile. The depth of water over it varies from ten to fifteen fathoms, but, like the Skerries, there are depressions at various places. Immediately inside it the depth varies from thirteen to eighteen fathoms. The presence of this bank is of great interest, and the water over it almost always displays some disturbance.

As we pass towards Berry Head we find a deep channel within half a mile from the shore. On one occasion during May, 1902, a depth of thirty fathoms was recorded a quarter of a mile off the Cod Rock. The greatest depth given by any chart for this place is twenty-eight fathoms, and the Admiralty charts give only twenty-three. Outside the channel the depth of water is but seventeen to nineteen fathoms. Apart from these exceptions, the depths given by the Admiralty charts were found to agree fairly well with the records.

The soil in the Great West Bay varies from rough gravel and stones to fine sand and mud. Along the thirty-fathom line we find for the most part gravel and coarse sand, except at the two extremes. Five to six miles off the Start in an easterly direction, with Prawle Point on a line with the Start, there are banks of fine sand, which in the beginning of summer are covered by mud. This region is called the "Corner" by the Brixham fishermen, and, it will be noticed, lies straight off Dartmouth fairway. The depth over these banks is about thirty fathoms, and they are surrounded by water one to two fathoms deeper.*

* These banks are not to be confounded with Start Bank, which lies to the south of Start Point. See chart. 
As we pass along the thirty-fathom line and come to a point east by south of Berry Head, and south-west of Portland, we meet with a long bank or ridge of gravel, shells, and stones, which extends on to the rocks off Portland. This ridge is not shown on the smaller charts, but on the large chart of the Channel by Laurie it is significantly marked as "rotten ground," "coarse," and "sand and small stones." The first designation probably refers to the oyster and pecten shells which abound there in great quantities. The Brixham men call the ridge the "Scruff," and state that there used to be a western scruff of similar material in the Corner off the Start. The western limit of the Scruff is not clearly defined, but there is a break between it and what are called the "Clumps," the rough ground about fifteen to twenty miles off the Start. The Scruff and the Clumps are, however, of similar nature, and if we continue the same line westward we come upon the rough stony tract which forms the centre of the Channel.

The breadth of the Scruff seems to be about a quarter of a mile. Its outer boundary is parallel and close to the line followed by steamers passing up and down Channel from Portland to the Start. Within the line of the Scruff there is a broad band of bright yellow sand of medium to coarse quality, which the trawlers call " biscuit dust." This extends as far as the twenty-five-fathom line, where it changes to fine sand of a brown colour. This continues all round Lyme Bay until fifteen to sixteen fathoms are reached, when it gives place to rocky ground with intermediate patches of sand.

The western side of the Great West Bay is just the reverse of the eastern. Outside the Skerries we find gravel and coarse sand, but from there onward to off Teignmouth Bay the offshore grounds consist of fine sand and mud. This, in fact, is the peculiarity of the western part, that its central region, from twenty-seven fathoms right into Torbay, consists of mud (Tables I. and II., p. 540, Sample x.). There is no place in the English Channel, nor, so far as I can discover, round the British coasts, where mud-non-estuarine in character-has accumulated to such an extent as off Berry Head.

Within Start Bay, and along a narrow strip from Berry Head to the Mewstone off Dartmouth, the bottom-soil is quite different. Gravel and coarse to medium sand are found between the rocks off Downend, and on the bank off the East Blackstone. There is a tract of mud across the mouth of the Dart until we come to the centre of Start Bay off Torcross. The mud then gives place to fine yellow sand, and this, towards the shore on the one hand and the Skerries on the other, grades into coarse sand. Along the beach from Blackpool to Start Point the soil gradually changes from medium sand, through mixed sand and stones on Slapton beach, to a fairly uniform spread of gravel and pebbles at Hallsands. 
A dredging obtained off Blackpool, where the beach is of sand, showed that other materials were present in the deeper waters. It is well known that the sand of the beach rests on a clay bottom, which is frequently uncovered by storms. At the eastern corner, in five fathoms of water, this clay was found free of sand, but contained small pebbles similar to those on the beach at Hallsands. These pebbles were well rounded, showing that they must have travelled about a good deal until trapped in the clay.

Apart from the beach the coarsest sand in Start Bay is to be found along the margins of the Skerries Bank. Samples obtained there after a gale from the east on the 4th February, 1902, showed that the material varied from coarse gravel to fine sand, stones being absent, and silt practically so (Tables I. and II., Samples ii.-vi.).* Of five samples taken the coarsest was 4.760 on the average, or between coarse sand and fine gravel, whilst the finest was 6.049 , i.e. medium sand. The finest material obtained on that date was 6.86 on the average, i.e. almost entirely fine sand (Sample vii.), and this was got, not on the Skerries Bank, but half a mile from the shore between Hallsands and Beesands. In the summer and autumn, however, the fine sand is found on the top of the Skerries Bank, and the easterly gale is responsible for its having been found within the bay near the shore.

Off Teignmouth Bay, again, we find a peculiar distribution of the bottom-soil. From Hope's Nose to off Teignmouth there is a stretch of hard ground on which oysters are fairly abundant. As showing the trend of the current in Teignmouth Bay, it may be mentioned that the empty shells congregate in masses behind the Orestone on the Torbay side. Outside this hard though muddy ground, there is a long shelving bank, which the Brixham fishermen call the "Ledge." This extends out in an easterly direction, and has several patches of rocks and coarse gravel. On the inner side of the oyster ground lies a stretch of muddy ground, which, within six fathoms, gives place to sand. The ground on the northern portion of the bay is very variable throughout the year. When first worked over during the autumn of 1901, it was a stretch of uniform sand from off Teignmouth to the fairway buoy off Exmouth; but in the spring of 1902 the sand was swept away, and a bed of large stones running out from Clerk Rock to over a mile from the shore was laid bare. This bed was still uncovered in July, 1902.

It only remains now to consider the relations between the tides and currents on the one hand, and the bottom-soil on the other. The effect of storms is to disturb the actual condition of things, but with fairly regular currents the tendency of soil is to take up a state of

* The grading of the soil is as given by E. J. Allen, "On the Fauna and Bottomdeposits near the Thirty-fathom Line from the Eddystone to Start Point" (Jour. M. B. A., vol. v. p. 378). 
equilibrium so that one kind is present at one place and others at another. Looking at the matter broadly, we may say that wherever a current is running we find stones, but where there is comparative calm we find sand or mud.

It has been shown that the Great West Bay is the centre of reciprocating currents in the Channel; further, that the main tidal stream does not penetrate far into the bay, and consequently that the current inside is less than one knot per hour at full and change of moon, whereas outside it is over two. These causes combined bring about a state of comparative calm within the bay, more especially to the westward side and in the centre, and it is there we find the finest bottom-soil of the whole region.

At the head of the bay, i.e. off Beer Head, it was pointed out that the tides set round a complete circle within the twelve hours, and the tendency of the currents, therefore, is to carry away from this centre whatever material may be movable. We thus find that along the northern shore the ascent to the beach is comparatively rapid, i.e. deep water approaches close to the shore, and, secondly, that the ground is mostly hard and rocky, with a few patches of mud and sand between the rocks.

As we pass from the head of the bay along its two arms, it has been shown that we meet with two currents, which gradually increase in velocity and strength as they approach and finally pass round the two extreme points. On the one hand, at Portland this current is made up of the flood-tide and an eddy from the ebb, and is of great velocity-greater than the outside main tidal stream; on the other hand, at Start Point the current arises from the ebb-tide and an eddy from the flood, and is comparatively weak. Both these currents flow in their respective directions nine hours out of the twelve, and their constancy and duration are considered to be due to the heaping up of the waters by the tide at the head of the bay.

On the eastern arm towards Portland there can be little doubt that the east-going stream has considerable influence in keeping the bottom clear of sand and mud, and thus leaves the rocks bare and uncovered. Along this arm the rocks of the coast project outwards as far as the fifteen-fathom line. The seas raised by the gales from the south and south-west break heavily on this eastern arm, but their influence is mostly destructive, and the sand and mud would tend to return to their former position were it not for the steady, though at the beginning slow, current which is in reality the effective agent in the transference of sand from west to east. It is to the excess of the easterly-going current over that going to the west that Vaughan Cornish * ascribes 1898).

* "The Grading of the Chesil Beach Shingle" (Proc. Dorset Nat. Hist. Field Club, 
the peculiar formation of the famous Chesil Beach. As is well known, this beach begins near Bridport with fine sand and extends a distance of sixteen miles towards Portland, the sand gradually changing to gravel and pebbles and thence to stones. The grading is so nice that fishermen are said to be able to tell where they are, even in the dark, by merely examining the materials of the beach. According to Cornish, the east-going current of nine hours' duration is able to carry along materials to a greater distance than the west-going current of only three hours. Consequently the heavy stones are steadily being carried to the eastward, until they are trapped by the projecting "island" of Portland, which acts as a natural groyne. The lighter materials remain longer in suspension and are carried onwards beyond the Bill to the Shambles. The west-going stream may carry the suspended sand backwards towards Bridport, but on the whole the drift is easterly.*

It has been mentioned that a returning eddy makes its appearance in Start Bay after high water by the shore, and though this eddy has not been definitely traced farther back than Berry Head, there are indications of its presence even in Teignmouth Bay. In the centre of the latter bay the tides are scarcely felt, and the trend of the currents on the shore is in opposite directions at Teignmouth and Exmouth. The former seems to be due to the returning eddy, which, though weak, tends to deaden the flood-tide, whilst the latter is due in part to the conjoined currents setting directly on to the shore. At the lower end of the bay we have clearer evidence of the eddy in the strong current which rushes through between the Orestone and the mainland on the ebb, and in the accumulation of material from Teignmouth Bay on the Torbay side of the Orestone. + In Torbay itself the only evidence I have found for the presence of the eddy is that the trend of objects from the Brixham side of the bay is past the breakwater and on to Berry Head. Off Berry Head we have the deep, though narrow, channel close in to land, which seems unmistakable evidence of a strong eddy, and over Mudstone Ledge the eddy definitely makes it appearance. Off Downend, again, we find a sandbank separated from the land by a deeper channel, which has probably been formed by the conflict of the flood-tide flowing easterly on the outside with the eddy going to the west on the inside. Lastly, the whole appearance of Start Bay is evidence of the presence and great influence of the eddy.

On the chart it will be noticed that the depth contour lines in Start

* According to Wheeler (loc. cit.) there is also a distinct northerly current flowing along the island, and this accounts for the greater accumulation of material at Chesilton, which lies at the bend where the island begins to separate from Chesil Beach.

+ See foot-note, p. 533. 
Bay are just the reverse of those in other parts, i.e. they are opposed to the direction of the flood-tide. The opening into the bay lies between the Skerries Buoy and the Mewstone, whilst its head is at Hallsands. This shows that the currents in the bay tend in the main to go from the Dartmouth end towards the Start. The presence of the Skerries Bank undoubtedly has a great deal to do with the opening of the bay from the north-east, but it seems clear that this bank must itself have been formed under the influence of the eddy. Since the latter is running down through Start Bay for nine hours out of twelve, it follows that for three hours out of twelve it is opposing the oncoming flood-tide off the Start, and the materials it is carrying down in suspension eventually come to rest either on the beach or along the line of demarcation. This seems to explain clearly enough why the Skerries Bank is present off Start Bay, and also why it is broader near the Start than at the other end near the buoy. The tendency is for the sand to accumulate more and more at the south-west corner, because it is there that the opposing currents meet and are most in conflict, causing the water to be comparatively calm, and it is only the deep channel cut out by the eddy between the bank and the land which prevents the south-west corner from being filled up by sand.

Along the beach from Slapton to Hallsands we have the Chesil Beach reproduced on a smaller scale. The finer sand mixed with stones and gravel is found on Slapton Sands, whereas at Hallsands there is practically nothing but pebbles. The theory of Cornish seems to apply equally well here. The eddy and the ebb together being in excess of the flood, carry all materials down the bay. The heavier stuff comes to rest sooner under the lee of the projecting promontory of Start Point, and is thus deposited on the beach at Hallsands, whilst the lighter sand is carried onwards and deposited on the Skerries.

In conclusion, the comparison between Chesil Beach and the beach in Start Bay may be recapitulated. In both cases we have currents flowing for nine hours one way and three hours the other, a projecting promontory at each which acts as a natural groyne, a grading of the beach materials from fine to coarse in the direction of the more prolonged current, and the presence of a large sandbank offshore. Further, both beaches have been raised in great part, if not entirely, by the action of these currents, and a stretch of water has thereby been enclosed-in the one case Slapton Ley, behind Slapton Sands, in Start Bay; in the other case the Fleet, near Portland.

When more samples of the bottom-soil have been obtained it will be possible to push the comparison still farther. 
I. SAMPLES OF THE BOTTOM-SOIL, SHOWING THE PROPORTIONS OF THE DIFFERENT KINDS OF SAND.

SAMPLES.

\begin{tabular}{|c|c|c|c|c|c|c|c|c|c|c|}
\hline GRADE. & I. & II. & III. & Iv. & v. & vI. & vII. & viII. & Ix. & $\mathrm{x}$. \\
\hline I. Stones . & $\cdots$ & $\cdots$ & $\cdots$ & $\cdots$ & $\cdots$ & $\cdots$ & $\cdots$ & $\cdots$ & $\cdots$ & $\cdots$ \\
\hline II. Coarse Gravel & $\ldots$ & 0.50 & 0.58 & $0 \cdot 70$ & $4 \cdot 30$ & $0: 37$ & $0 \cdot 25$ & trace & $3 \cdot 20$ & $\ldots$ \\
\hline III. Medium Gravel & $1 \cdot 35$ & $2 \cdot 60$ & $3 \cdot 10$ & $2 \cdot 40$ & $15 \cdot 60$ & $2 \cdot 71$ & $0 \cdot 10$ & 0.42 & $5 \cdot 50$ & $1 \cdot 4$ \\
\hline IV. Fine Gravel & $3 \cdot 50$ & $4 \cdot 00$ & $7 \cdot 92$ & $4 \cdot 50$ & $21 \cdot 00$ & $4 \cdot 61$ & $0 \cdot 20$ & $1 \cdot 65$ & $11 \cdot 20$ & $\cdot 68$ \\
\hline V. Coarse Sand & $4 \cdot 45$ & $5 \cdot 80$ & $10 \cdot 25$ & $5 \cdot 30$ & $19 \cdot 20$ & $6 \cdot 30$ & $0 \cdot 25$ & $2 \cdot 37$ & $12 \cdot 30$ & $\cdot 78$ \\
\hline VI. Medium Sand . & $59 \cdot 70$ & $80: 30$ & $71 \cdot 85$ & 70.50 & $38 \cdot 20$ & $56 \cdot 00$ & $11 \cdot 05$ & $61 \cdot 14$ & 50.50 & 16.0 \\
\hline VII. Fine Sand & .. & 6.80 & $6 \cdot 30$ & 16.60 & $1 \cdot 70$ & 30.01 & $87 \cdot 80$ & $34: 41$ & $17 \cdot 30$ & $74 \cdot 0$ \\
\hline VIII. Silt & $\ldots$ & trace & $\ldots$ & $\ldots$ & trace & trace & 0.35 & trace & trace & $7 \cdot 2$ \\
\hline
\end{tabular}

Note.-I am much indebted to Mr. R. H. Worth for kindly working out Samples II. to VIII.

\section{GROUND WHERE SAMPLES WERE OBTAINED AND AVERAGE CONDITION OF SAMPLES.}

No. Ground, Depth, and Date.

I. Close to Skerries Buoy on inner side; $11 \frac{1}{2}$ fathoms; January 30 , 1902

Average.

-II. Close to Skerries Buoy on inner side, after easterly gale; $12 \frac{3}{4}$ fathoms ; February 4, 1902 . $\quad . \quad . \quad . \quad 5.83$

III. Close to Skerries Buoy on outer side; 15 fathoms ; February 4, $1902 \quad 5 \cdot 686$

IV. On line Skerries Buoy to Start Lighthouse ( $\frac{1}{2}$ mile); 10 fathoms; February 4, 1902 . . . . . . 5.923

V. On line Skerries Buoy to Lighthouse (half-way); 10 fathoms; February 4, 1902

VI. South-west corner of Skerries Bank, opposite Hallsands, on line Buoy to Lighthouse ; 10 fathoms ; February 4, 1902 . 6.049

VII. Midway between Hallsands and Beesands ( $\frac{1}{2}$ mile offshore); $9 \frac{1}{2}$ fathoms ; February 4, 1902 . . . . . 6.86

VIII. Off Torcross (2 miles); $7 \frac{1}{2}$ fathoms ; February 4, 1902 . . . 6.274

IX. On line Skerries Buoy to Lighthouse ( $\frac{3}{4}$ mile); 16 fathoms; February 4,1902 . . . . . . 5513

X. Four miles off Berry Head (E. $\frac{1}{2}$ S.) ; 24 fathoms; April 16, 1902 . 6.82 